\section{Towards baseline air pollution under COVID-19: implication for chronic health and policy research for Delhi, India}

\author{
Gufran Beig ${ }^{1, *}$, Mohan P. George ${ }^{2}$, \\ Saroj K. Sahu ${ }^{3}$, Aditi Rathod ${ }^{1}$, \\ Siddhartha Singh $^{4}$, Shruti Dole ${ }^{1}$, B. S. Murthy ${ }^{1}$, \\ R. Latha ${ }^{1}$, Suvarna Tikle ${ }^{1}$, H. K. Trimbake ${ }^{1}$ and \\ Rajanikant Shinde ${ }^{1}$ \\ ${ }^{1}$ Indian Institute of Tropical Meteorology (Ministry of Earth Sciences), \\ Pune 411 008, India \\ ${ }^{2}$ Delhi Pollution Control Committee, New Delhi 110 003, India \\ ${ }^{3}$ Utkal University, Bhubaneshwar 751 004, India \\ ${ }^{4}$ India Meteorological Department, New Delhi 110 003, India
}

The Megacity of Delhi, home to 19 million inhabitants, is infamous for its poor air quality mainly due to anthropogenic emissions. While the COVID-19 pandemic is a health emergency, lockdown due to it saw an unprecedented decline in emission sources of pollutants by $\sim 85 \%-90 \%$ in Delhi, resulting in sharp decline in the concentration of majority of pollutants. Here we report the experimental estimate of baseline level that is defined as the minimum level reached after lockdown under consistent fair weather condition of major criteria pollutants. This may be considered as an indicator of the background levels to which the population is chronically exposed. The consequences of such chronic air pollution exposure are excess respiratory and cardiovascular morbidity and mortality which are reported to be more serious than severe pollution episodes by epidemiologists. As the lockdown which was imposed on 24 March 2020, was extended during April and May, we present the prevailing ambient pollution levels and compare them with the baseline levels. Results are based on India's largest monitoring network of 34 stations in Delhi. The findings are critical for policymakers to fine-tune ambient air quality standards and regulations leading to the development of effective risk management policies and control strategies.

Keywords: Air pollution, anthropogenic emissions, baseline level, COVID-19 pandemic.

URBANIZATION has made a majority of megacities in the world as hot spots for air pollution. India's capital city, Delhi, is considered as one of the highly polluted megacities in the world (https://www.who.int/airpollution/ data/cities/en/), where locally generated anthropogenic emissions are largely responsible for deteriorating air quality due to short-lived pollutants. In addition, for a landlocked city like Delhi, the long-range transport of

*For correspondence. (e-mail: beig@tropmet.res.in) pollution, crop burning and dust storm on seasonal basis also contribute significantly to extreme pollution events ${ }^{1}$. Sources ranging from vehicles, re-suspended dust, industrial activities, burning of coal, dung and wood for cooking and heating, crop stubble burning, etc. affect Delhi. COVID-19, an infectious disease caused by the newly discovered coronavirus, has become a serious pandemic at present, resulting in lockdown. However, there is perhaps a silver lining in that it has opened up opportunities of air quality research, during particularly, in a megacity like Delhi, where it was virtually impossible to halt all major sources of pollutant emissions in the normal course. The prolonged period of more than a month of lockdown provided us a unique opportunity to estimate the baseline concentration of various pollutants for Delhi. The background concentration is fundamentally defined as the ambient level of pollution that is not produced by local sources of pollution ${ }^{2}$. The pollutants that advect in from the outside, or which would have been present naturally, are called background pollution (http:// glossary.ametsoc.org/wiki/Background pollution). However, in the present study, we define the terminology 'baseline level'. It is representative of the lowest level of background air pollution. This minimum level can be achieved under calm and uniform weather conditions (stagnant), where contribution of transport and extreme weather gets minimized. So in the present study, baseline level is more like an 'indicator of background levels'. The baseline level is the level to which the population is chronically exposed and hence greatly relevant to epidemiological research. To better understand the adverse health effects associated with air pollution, accurate exposure assessment is essential. Some cities may be highly polluted, but the health outcome will depend on the exposure. In general, pollution exposure greatly varies from person to person based on his/her mobility and local micro-environment in which a person spends maximum amount of time. Hence, the entire population is not necessarily exposed to uniform ambient high or low levels all the time. As the lockdown was nationwide, the advected or transported pollution was minimum. The baseline levels of pollution are mainly produced due to natural sources and remain under steady state, resulting in a baseline level of these chemicals and is maintained in the absence of any additional sources of emissions. Such emission scenario was nearly impractical in a highly populated megacity like Delhi. Thus experimental estimates of this lowest fraction of ambient air pollution were unavailable until now and research had not significantly addressed the same. However, some modelling studies and statistical estimates based on long series of air pollution data are available to understand background estimates $^{2}$, but these results have their own inherent shortcomings as they rely on assumptions and are not validated. While framing the national ambient air quality standards, the baseline pollution levels play an important 


\section{RESEARCH COMMUNICATIONS}

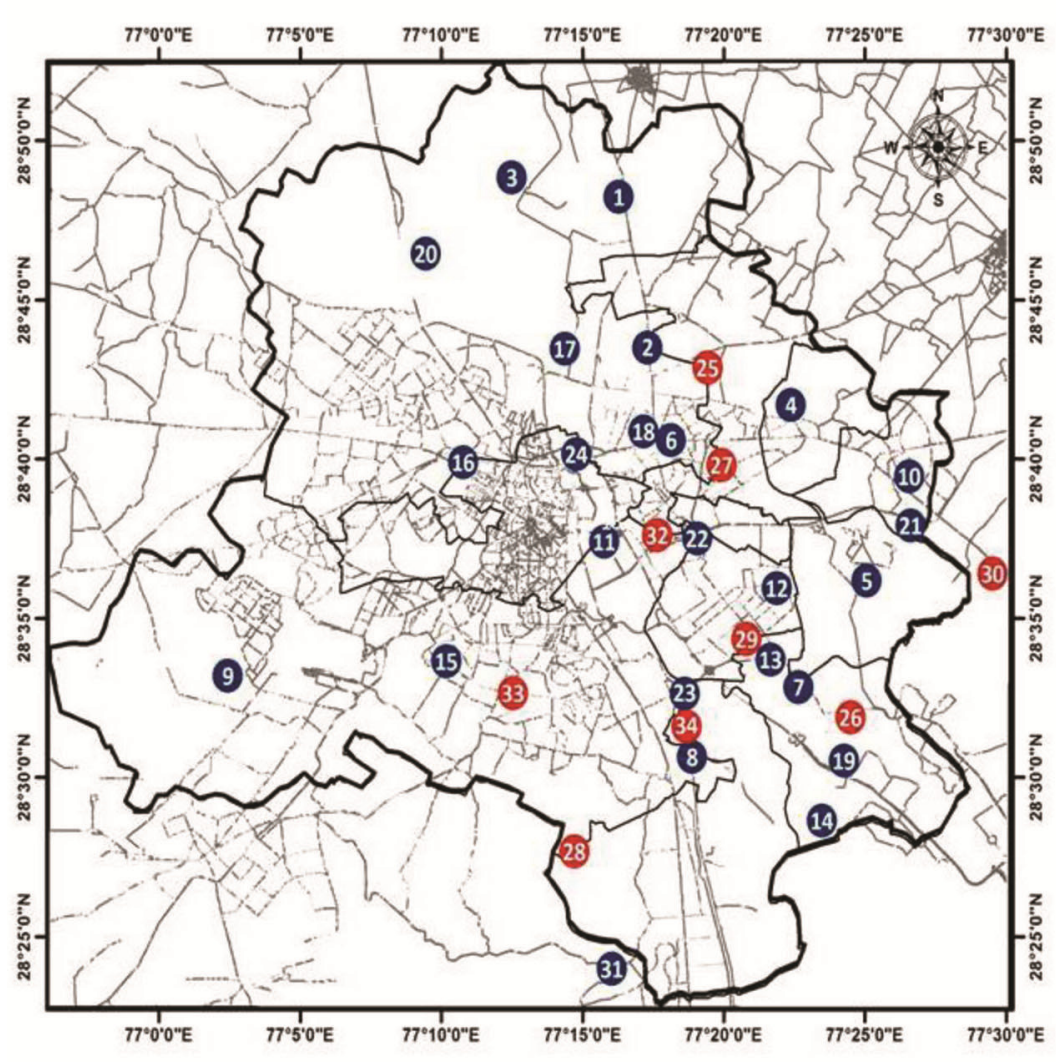

\begin{tabular}{|c|l|}
\hline Sr.no & \multicolumn{1}{|c|}{ Station name } \\
\hline 1 & Alipur \\
\hline 2 & Jahangirpuri \\
\hline 3 & Narela \\
\hline 4 & SoniaVihar \\
\hline 5 & Patpargani \\
\hline 6 & AshokVihar \\
\hline 7 & NehruNagar \\
\hline 8 & Sri Aurobindo Marg \\
\hline 9 & Najafgarh \\
\hline 10 & VivekVihar \\
\hline 11 & Pusa \\
\hline 12 & National Stadium \\
\hline 13 & JLN Stadium \\
\hline 14 & Shooting range \\
\hline 15 & Dwarka \\
\hline 16 & Mundka \\
\hline 17 & Rohini \\
\hline 18 & Wazipur \\
\hline 19 & Okhla \\
\hline 20 & Bawana \\
\hline 21 & AnandVihar \\
\hline 22 & MandirMarg \\
\hline 23 & PunjabiBagh \\
\hline 24 & R K Puram \\
\hline 25 & CVR \\
\hline 26 & CRRI \\
\hline 27 & DU \\
\hline 28 & IMDA \\
\hline 29 & IMDL \\
\hline 30 & Noida \\
\hline 31 & NISEG \\
\hline 32 & NPL \\
\hline 33 & PALAM \\
\hline 34 & IIT Delhi \\
\hline & \\
\hline
\end{tabular}

Figure 1. Map of National Capital Territory, Delhi, India where the 34 air-quality monitoring stations are located in different micro-environments.

role. A better understanding of the baseline level is important for regulatory purpose by local authorities to frame control strategies. Epidemiological studies have provided evidence linking daily levels of ambient air pollution to adverse health impacts as the population is continuously exposed to it for a long-period ${ }^{2}$. There are a number of evidence which confirm that a moderate increase in long-term exposure to baseline ambient air pollution will increase the prevalence of respiratory and atopic indicators in children ${ }^{3}$. Determining the population's health risks due to ambient baseline air pollution is critical to the development of effective risk-management policies and strategies ${ }^{4}$, and warrants more research for a better understanding. Here we provide an estimate of the baseline concentration of most critical pollutants, namely PM10, PM2.5, $\mathrm{NO}_{2}, \mathrm{CO}$ and $\mathrm{SO}_{2}$ for Delhi, and also discuss about ozone. We mention the benefits of such a study in framing the ambient air quality standards and advancing health related research.

The present study focuses on Indian capital, National Capital Territory (NCT)-Delhi (Figure 1). Delhi is a highly urbanized landlocked city situated at an elevation of $216 \mathrm{~m}$ amsl, covering an area of $1483 \mathrm{sq}$. $\mathrm{km}$. It has a population of about 17 million according to the Census of India 2011, which is rapidly growing. This study uses data obtained from the largest monitoring network of Delhi, comprising 34 on-line automatic air quality monitoring stations operated by the country's first air quality forecasting project of the Ministry of Earth Sciences (MoES), Government of India (GoI), SAFAR (System of Air Quality and Weather Forecasting and Research $)^{5}$ and Delhi Pollution Control Committee (https://www.dpcc.delhigovt. nic.in/indexdup.php), Government of Delhi. These monitoring stations are spread around different microenvironments of Delhi and the surrounding regions to be representative of NCT-Delhi. The measured air pollutants include PM10, PM2.5, ozone $\left(\mathrm{O}_{3}\right)$, oxides of nitrogen $\left(\mathrm{NO}_{x}\right)$, carbon monoxide $(\mathrm{CO})$ and benzene. The data obtained from the monitoring network are time resolved and binned for $1 \mathrm{~h}$ interval for further analysis to get the $24 \mathrm{~h}$ mean daily concentration. The observed daily levels of these pollutants over Delhi during the study period were averaged across all stations spread in different microenvironments of the megacity. Averaging removes inhomogeneity in the datasets and can best be considered as representative of the city area, according to the World Meteorological Organization (WMO) guidelines ${ }^{6,7}$. The mass concentrations of PM10 and PM2.5 were monitored based on the beta-ray absorption method and The mass concentration of PM2.5 was continuously monitored by on-line analyser employing beta attenuation monitor approved by US-EPA (BAM-1020; Met One Instruments, 


\section{RESEARCH COMMUNICATIONS}
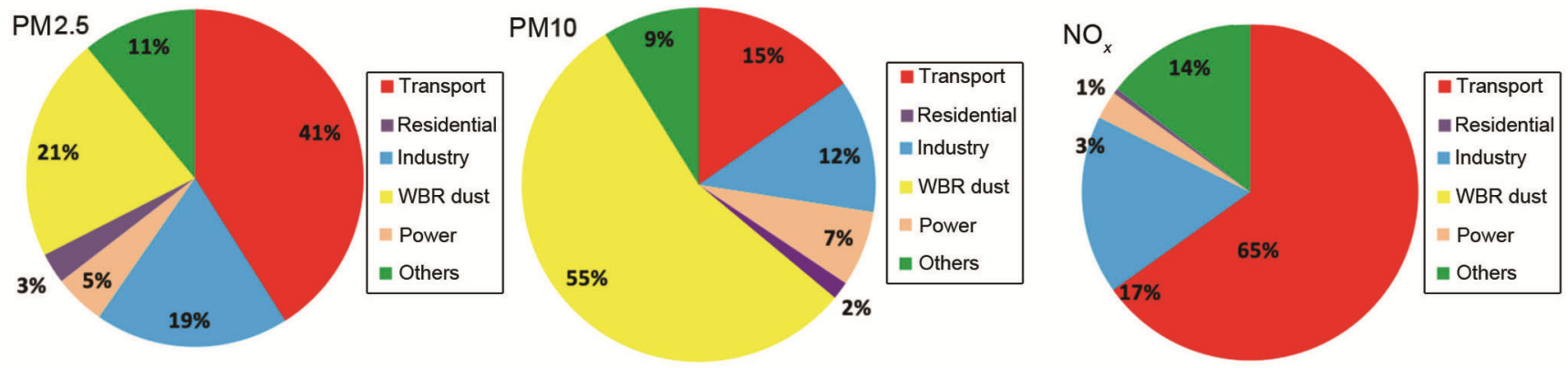

Figure 2. Relative share of various sources of emissions in $\mathrm{PM} 2.5, \mathrm{PM} 10$ and $\mathrm{NO}_{x}$ under normal case.

Inc, USA $)^{8}$, which uses the principle of beta-ray attenuation. The chemiluminescence reference method was used for the measurement of $\mathrm{NO}_{2}$ and oxides of nitrogen $\left(\mathrm{NO}_{x}\right)$, which is also US-EPA approved. CO was measured employing non-dispersive infrared detectors using gas filter correlation carbon monoxide analyser, whereas ozone analyser works on the principle that ozone particles absorb ultraviolet (UV) light at a wavelength of $254 \mathrm{~nm}$. The amount of UV light absorbed is proportional to the amount of ozone present in the airspace. The amount of UV light absorbed in the chamber was interpreted as ozone concentration. The BTEX analyser was used for benzene and related parameters. It separates the targeted compounds based on gas chromatography and analyses them using photo-ionization detection. The instruments were maintained and operated according to the standard specifications for robust quality control and quality assurance without any compromise. The instruments were either US-EPA-approved or certified by Bureau Veritas Certification (ISO9001) for quality control. US-EPA's Standard Operating Procedures were adopted for instrument calibration and maintenance. Several standard calibrations checks starting from zero to span calibrations were done routinely according to the specified guidelines. Detailed information about the calibration procedure can be found in title 40 of the Code of Federal Regulations (CFR) part 50 (http://www.law.cornell.edu/cfr/text/40/ part-50).

The lockdown resulted in an inconceivable emission scenario, which has been considered in this study by downscaling the regular SAFAR emission inventory prepared earlier and released by MoES, GoI ${ }^{9}$. The lockdown activity data and status report obtained from local authorities were applied in the regular emission inventory are get controlled emission scenario. The methodology of the emission inventory can be found elsewhere ${ }^{9}$, and hence is not discussed here in detail. Lockdown resulted in the reduction of major sectorial emissions by up to about $85-90 \%$, except biofuel emissions, which remained unchanged. Figure 2 shows the relative contribution of emissions of PM10, PM2.5 and $\mathrm{NO}_{x}$ from various major sources, namely transport, industry, power wind-blown dust, biofuel (residential) and others (viz. brick kiln, solid waste, open burning, etc. $)^{9}$. The relative share of the residential sector among all sources in PM2.5, PM10 and $\mathrm{NO}_{x}$ was found to be $3 \%, 2 \%$ and $1 \%$ respectively, which is insignificant. This marginal contribution from the residential sector in NCT-Delhi is mainly due to providing LPG under GoI's successful special drive, viz. 'Pradhan Mantri Ujjwala Yojana'. As evident from Figure 2, maximum share in PM2.5 (41\%) and $\mathrm{NO}_{x}(65 \%)$ is from the transport sectors, whereas for PM10 maximum share is from re-suspended wind-blown dust (55\%). The emissions from transport and wind-blown dust were almost negligible after the imposition of strict lockdown. All industries were closed. In fringe rural areas of Delhi, usage of wood for cooking has increased slightly due to some complications and restrictions in obtaining cleaner fuel, but significant reduction of its usage within city limits by street vendors is assumed to have compensated the incremental enhancement. In terms of overall pollution levels, the relative contribution of bio-fuel emission is not significant ${ }^{9}$, in case of Delhi, the uncertainty in estimating the baseline concentrations of various criteria pollutants is found to be negligible. However, uncertainty in $\mathrm{CO}$ where share of bio-fuel is relatively high lead to error in analysis. Figure 1 shows the map of Delhi and surrounding area, where locations of various monitoring stations are marked. There are widespread in and around Delhi region in different microenvironments.

The analysis was done using the above-mentioned data. Figure 3 shows the time series of these pollutants during 20 February to 14 April 2020 in Delhi, which includes periods before and after the lockdown. The data were compared with pollution levels of 2019 during the same period for reference purpose. Due to COVID-19, although human activities started to reduce significantly from the second week of March, the official lockdown started only after 23 March 2020. Two regimes, namely before lockdown (normal) and after lockdown are marked with a vertical line in Figure 3 at the start of 24 March 2020. Significant decline in the levels of all pollutants was noticed during the lockdown, except ozone, compared to the period before lockdown. Levels of a majority of pollutants fell sharply immediately after the lockdown and concentration of pollutants touched the saturation 

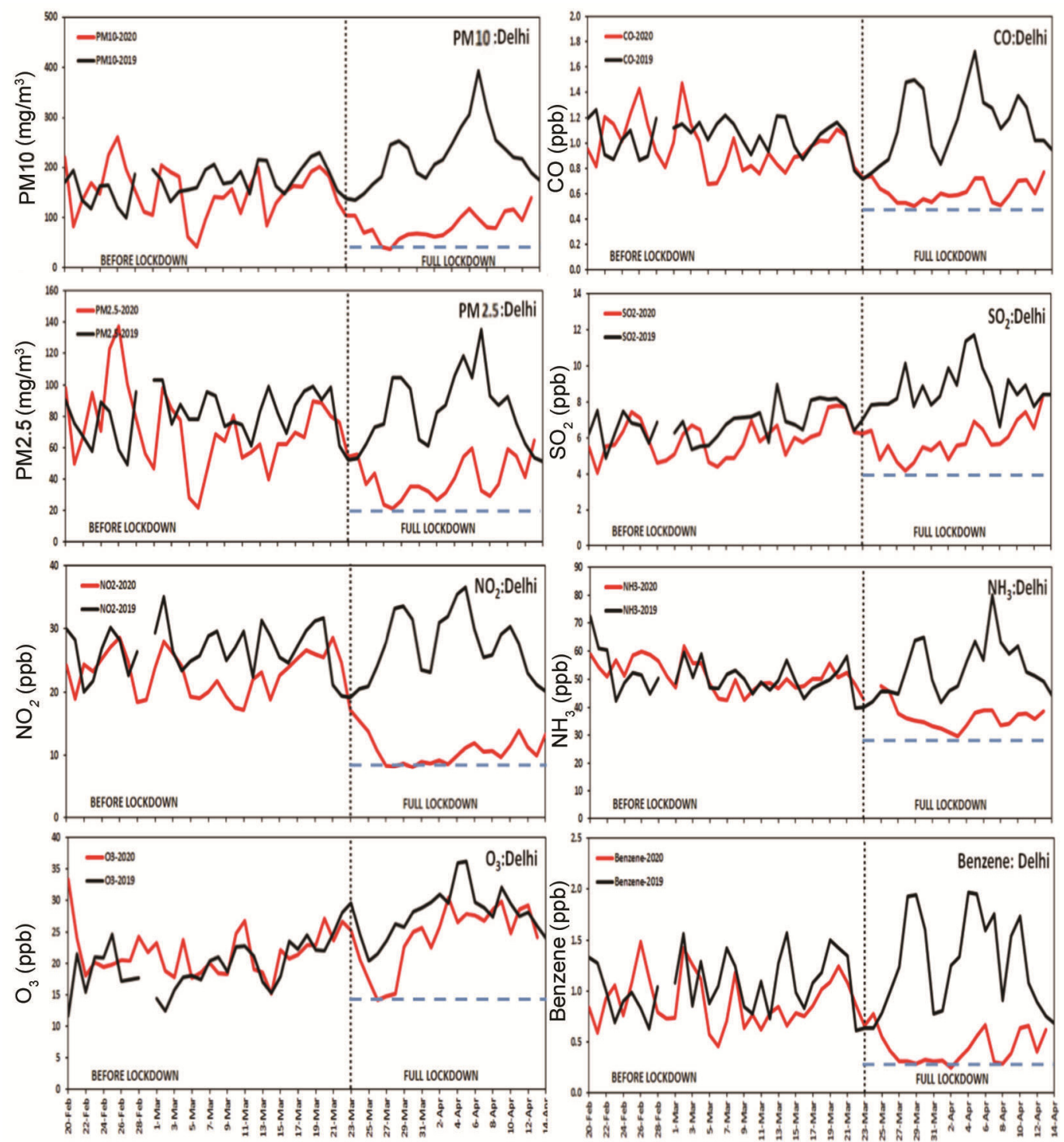

Figure 3. Time series of the concentration of eight major pollutants in Delhi from 20 February to 14 April 2020 , covering the period before and after the COVID-19 lockdown (divider at $23 \mathrm{March}$ ). Data of the same parameters for the identical period of 2019 are also shown for comparison. Blue dotted horizontal line indicates the lowest level at which the pollutant concentration reached saturation point, known as permanent or base level. Table 1 shows the uncertainty associated with each of the pollutants.

level within a few days, beyond which further decline was not possible. Here, the saturation level is defined as the level at which concentration of pollutants remains almost constant for at least 2-3 days after a sharp fall due to drastic decline in emissions during the lockdown. In the present case, each pollutant of Delhi reached the saturation level within 4-6 days after lockdown, beyond which a steady level was maintained, barring a few exceptions. During the time from lockdown to saturation period, the weather was fairly uniform and transport level winds required for advection of short-lived pollutants in Delhi was quite low. Since lockdown was countrywide, the emissions of pollutants declined in larger region from where transport is possible. Due to the above meteorolog- ical factors, probability of significant share in observed pollution levels from external sources was very low. However, as lifetime of CO and ozone is relatively high, contribution from long range transport cannot be ruled out. However, all these factors are considered while estimating the uncertainty ${ }^{5,8}$. Hence, significant fall in the pollutant concentrations after lockdown can be directly attributed to near-negligible COVID-19 lockdown emission scenario. Based on the saturation level when it gets stabilized, the baseline concentration of various pollutants was determined and the blue dotted line is marked to calculate the target value. Table 1 shows the baseline levels of various pollutants in Delhi as determined in this study. The values shown in brackets are the margin of 
error associated with each parameter. The stated error is estimated as per the protocol by considering various factors of uncertainty ${ }^{5,8}$. The values in Table 1 may be assumed as baseline levels of the atmosphere for these pollutants within the stated uncertainty, which are supposed to be always present near the surface unless a strong external source through transport or weather disrupts the steady state; this may lead to increase or decrease of these levels. All the pollutants show a decline as evident from Figure 3, except ozone. In the case of ozone, it fell sharply immediately after the lockdown, but thereafter an increasing trend was observed. The basic ozone chemistry suggests that ozone will increase, at least temporarily, as emissions of the fossil fuel based nitrogen oxides go down. The relation between $\mathrm{O}_{3}, \mathrm{NO}_{x}$ and volatile organic compound (VOC) is driven by complex nonlinear photochemistry. In the presence of high NO, ozone concentrations are lowered through the process of $\mathrm{NO}_{x}$ titration. This consists of the removal of $\mathrm{O}_{3}$ through reaction with NO. Ozone in Indian megacities like Delhi follows the VOC-limited $\left(\mathrm{NO}_{x}\right.$-saturated) regime and generally remains low due to high amounts of $\mathrm{NO}_{2}$ as well as high $\mathrm{NO} / \mathrm{NO}_{2}$ ratio. However, immediately after the lockdown, at a certain point, ozone touched the lowest level and became steady when the loss due to titration stopped, and then it started to increase. We have marked the minimum value of ozone at the first sharp decline which remained low for 2-3 days as the baseline value. With uncertainty associated with complex chemistry of $\mathrm{O}_{3}-\mathrm{NO}_{x}-\mathrm{VOCs}$ mechanism, we do not intend to drive the conclusion/confirm on baseline level of ozone concentration in this work. It is noteworthy to mention here that during the lockdown, all anthropogenic emissions became negligible, except biofuel emissions from residential cooking. However, the impact of biofuel emission in Delhi for PM10, PM2.5 and $\mathrm{NO}_{x}$ is likely to be minimal and assumed to be negligible as discussed above, due to negligible relative share of biofuel emission (less than $3 \%$ ) in these pollutants (Figure 2). The baseline levels of PM10 and PM2.5 were found to be $38( \pm 8)$ and $22( \pm 6) \mu \mathrm{g} / \mathrm{m}^{3}$ respectively. The baseline value of $\mathrm{NO}_{2}$ was found to be $8( \pm 3) \mathrm{ppb}$, which is considered to be very high. It implies the dominant role of fossil-fuel emissions in influencing the base level of $\mathrm{NO}_{2}$, which often crosses the threshold level under moderate increase in fossil fuel emissions to trigger titration reaction for the destruction of ozone. This is one of the major reasons that ozone in Delhi often remains very low. The baseline levels for $\mathrm{CO}$, benzene, $\mathrm{SO}_{2}$ and $\mathrm{NH}_{3}$ were found to be $500( \pm 150) \mathrm{ppb}, 250( \pm 62) \mathrm{ppt}, 4( \pm 2) \mathrm{ppb}$ and 28 $( \pm 8) \mathrm{ppb}$ respectively. The uncertainty in $\mathrm{CO}$ baseline value was high, as contribution from long-range transport may influence the same due to its relatively long lifetime. It is stressed here that the levels of these pollutants are unlikely to fall below the stated baseline levels (without any strong external forcing) present in the atmosphere in steady state. Hence, it is emphasized that air quality index guidelines should consider base level concentration as unique markers that are determined in this work, in formulating ambient air quality standards for future work.

Figure 4 shows a comparison of baseline levels of different pollutants considered in this study with those of average observed values for April and May 2020. The country-wide lockdown was extended until the end of May 2020. However, as mentioned earlier, a consistent, calm weather condition prevailed in the last week of March when the lockdown was announced. Hence the concentration of air pollutants could reach a particular level, which we call baseline level. However, such condition could not continue for later period. The long-range and neighbouring transport processes, variability in local and distant weather started to play a significant role. The weather parameters play an important role in air pollution and changes from season to season. In addition, crop residue burning in rural India is a regular feature during winter and summer. However, during winter in Delhi, lower inversion layer, cooler temperature and calm wind conditions trap pollutants significantly and elevate their levels. In summer, the ventilation coefficient is high and inversion layer is inflated with warmer temperature, but the transport of dust from the desert area in Rajasthan and dust storms from long range, even across the border, lead to extreme pollution episodes. Due to the above processes, the levels shown in Figure 4 for April and May 2020 are relatively higher than the baseline levels in this study. The level of PM10 was found to increase significantly due to frequent dust lifting from neighbouring Rajasthan, and mild dust storms during May, as simulated by SAFAR air quality forecasting model five days in advance (http://safar.tropmet.res.in/). The level of PM10 in May $\left(\sim 140 \mu \mathrm{g} / \mathrm{m}^{3}\right)$ was found to increase more than three times compared to baseline levels. Similarly, the variability in PM2.5 was found to be significant. The lifetime of $\mathrm{CO}$ is quite high (more than a month) and hence significant amount of external transport elevated its level by two times in both months in spite of the lockdown. Due to the complex nature of ozone chemistry, we could

Table 1. Baseline levels or permanent concentration of different pollutants as derived in this study after the saturation level is reached amid unprecedented reduction in major sources of emissions during complete lockdown due to COVID-19

\begin{tabular}{lc}
\hline Pollutants & Delhi @COVID-19 baseline levels \\
\hline PM10 $\left(\mu \mathrm{g} / \mathrm{m}^{3}\right)$ & $38( \pm 8)$ \\
$\mathrm{PM} 2.5\left(\mu \mathrm{g} / \mathrm{m}^{3}\right)$ & $22( \pm 6)$ \\
$\mathrm{NO}_{2}(\mathrm{ppb})$ & $8( \pm 3)$ \\
$\mathrm{CO}(\mathrm{ppb})$ & $500( \pm 150)$ \\
$\mathrm{C}_{6} \mathrm{H}_{6}(\mathrm{ppt})$ & $250( \pm 62)$ \\
$\mathrm{SO}_{2}(\mathrm{ppb})$ & $4( \pm 2)$ \\
$\mathrm{NH}_{3}(\mathrm{ppb})$ & $28( \pm 8)$ \\
\hline
\end{tabular}

The values in brackets represent standard deviation. 

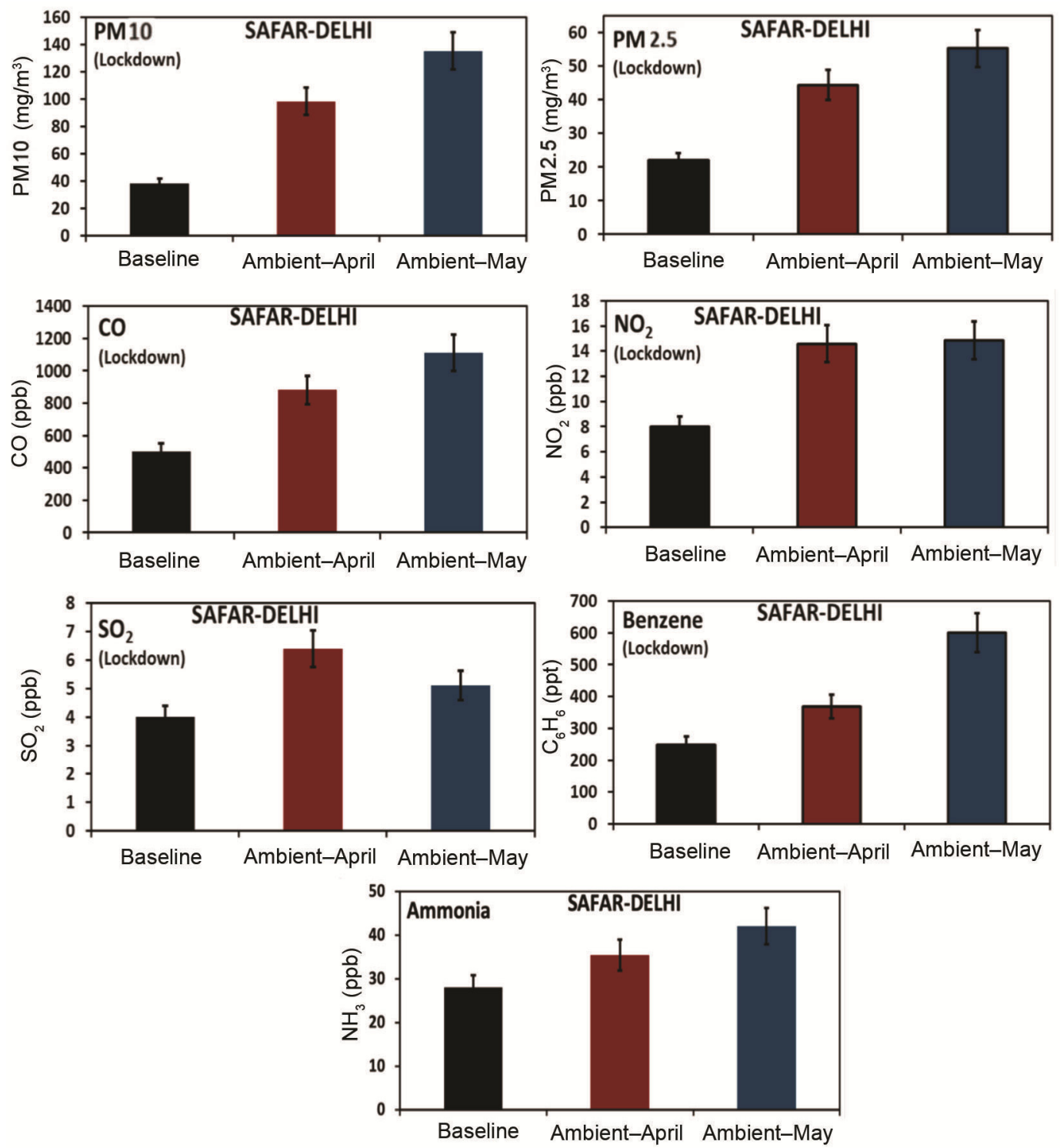

Figure 4. Baseline levels computed in this study for various pollutants in Delhi compared with the monthly averaged values of prevailing ambient levels under COVID-19 lockdown for April and May 2020.

not drive the baseline levels of ozone and hence it is not included in Figure 4; but its value was also found to increase. It should be mentioned that when the ambient levels for April and May 2020 (lockdown period) were compared with 2019 levels of the identical period, the lockdown levels were found to be significantly lower than the 2019 levels, except for ozone. The levels of $\mathrm{NO}_{2}$ increased to $14 \mathrm{ppb}$ and remained almost stagnant for both months. It is stressed here that the lockdown was the most stringent measure which could be implemented to stop anthropogenic emissions. However, even under this scenario, ambient levels crossed or levelled the Indian National Ambient Air Quality Standards (NAAQS) on several days (Figure 4). These ambient levels would be even higher in winter due to local meteorology. This implies that the prevailing NAAQS needs a revisit and there is scope for fine-tuning this in the perspective of economic development.

We have provided the minimum level of pollutants termed as baseline level under the lockdown scenario, which may be assumed as an indicator or marker of background levels. This is the most appropriate estimate under the unprecedented lockdown scenario, but not without constraints. Results are subjected to uncertainty that may be due to the presence of emission sources in spite of the lockdown, long-range transport and prevailing meteorology. Hence these results should be viewed with caution. In recent years, research in the field of air pollution and human health has begun to focus more on personal exposure from long-term baseline air pollution, which indicates more direct links with adverse impacts on human health $^{4}$. Baseline concentration, however, is slow to 
respond and hence provides a steady response to the overall air quality of a city, which may be described as 'slow-response exposure' but with chronic outcome. The consequences of chronic air pollution exposure are more serious in long term ${ }^{10}$. Results presented here may be helpful to policy makers to fine-tune guidelines for NAAQS and regulations to maintain a balance with economic development for progress of the nation.

1. Gufran Beig, S. K. et al., Objective evaluation of stubble emission of North India and quantifying its impact on air quality of Delhi. Sci. Total Environ., 2020; https://doi.org/10.1016/j.scitotenv. 2019.136126.

2. WHO, Glossary on Air Pollution, WHO Regional Publications, Europe Series No. 9, Regional Office for Europe, Copenhagen, Denmark, 1980

3. Pénard-Morand, C., Charpin, D., Raherison, C., Kopferschmitt, C., Caillaud, D., Lavaud, F. and Annesi-Maesano, I., Long-term exposure to background air pollution related to respiratory and allergic health in school children. Environ. Model. Softw, 2005, 35(10), 1279-1278.

4. Gómez-Losada, Á., Pires, J. C. M., Pino-Mejías, R., Modelling background air pollution exposure in urban environments: implications for epidemiological research. Environ. Model. Softw., 2018, 106, 13-21; https://doi.org/10.1016/j.envsoft.2018.02.011.

5. Beig, G. et al., System of Air Quality Forecasting and Research (SAFAR-India). GAW Report No. 217, World Meteorological Organization, Global Atmosphere Watch, Geneva, Switzerland, 2015.

6. Grimmond, S. et al., Establishing integrated weather, climate, water and related environmental services for megacities and large urban complexes - initial guidance, Global Framework for Climate Services, World Meteorological Organization, United Nations, Geneva, Switzerland, 2014.

7. Anand, V., Korhale, N., Rathod, A. and Beig, G., On processes controlling fine particulate matters in four Indian megacities. Environ. Pollut., 2019; doi:ENVPOL 2019 1529, 254 A, 113026.

8. http://pdf.directindustry.com/pdf/environnement-sa/mp101m-pm10-pm25-tsp-continuous-particulate-monitor/23554-578190.html (accessed on 3 April 2020).

9. Beig, G. et al., SAFAR-high resolution emission inventory of Megacity Delhi for 2018. Special Scientific Report, SAFARDelhi-2018-A, ISSN: 0252-1075, Indian Institute of Tropical Meteorology, Pune, 2018.

10. Menichini, E., Iacovella, N., Monfredini, F. and TurrioBaldassarri, L., Atmospheric pollution by PAHs, PCDD/Fs and PCBs simultaneously collected at a regional background site in central Italy and at an urban site in Rome. Chemosphere, 2007, 69 , $422-434$.

ACKNOWLEDGEMENTS. This work was supported by Indian Institute of Tropical Meteorology (IITM), Pune. We thank the Director, IITM and Secretary, Ministry of Earth Sciences for the support. Thanks are also due to the Delhi Pollution Control Committee. Sincere thanks to Dr Shailesh Nayak for motivating us to take up this challenging problem.

Received 20 May 2020; revised accepted 13 July 2020

doi: $10.18520 / \mathrm{cs} / \mathrm{v} 119 / \mathrm{i} 7 / 1178-1184$

\section{Economic incentives for sustainable legume production in India: a valuation approach internalizing risk sharing and environmental benefits}

\author{
Suresh Kumar ${ }^{1}$, Girish Kumar Jha ${ }^{1, *}$, \\ Dharam Raj Singh ${ }^{1}$ and H. Biswas ${ }^{2}$ \\ ${ }^{1}$ ICAR-Indian Agricultural Research Institute, \\ New Delhi 110 012, India \\ ${ }^{2}$ ICAR-Indian Institute of Soil and Water Conservation, \\ Research Centre, Bellary 583 104, India
}

The present study estimates the social cost of growing paddy, wheat and legumes as Rs 9484, 8804 and 1281 per ha respectively. Monetized value of overall risk in paddy, wheat and legumes is $R s$ 716, 650 and 1738 per ha respectively. An economic incentive consisting of risk and social benefits, to the tune of Rs 8611 and 9225 per ha over wheat and paddy respectively, should be provided for the production of legumes. The study highlights the need to internalize environmental benefits of legumes vis-à-vis competing crops, and accordingly cultivation of legumes needs to be encouraged through a proper mechanism of incentivization.

Keywords: Economic incentive, environmental benefits, legumes, risk sharing, rice, wheat.

INCLUSION of legumes in cropping systems makes the crop production system climate-change resilient, due to their ability to adapt to changing climatic conditions. This also helps in mitigating the impact of climate variability ${ }^{1}$. Moreover, legumes help in enhancing soil and human health $^{2}$. Taking cognizance of the contribution of legumes for sustainable food production and their role in eradicating hunger and malnutrition, the Food and Agriculture Organization, Rome, declared 2016 as the International Year of Pulses, and called for efforts towards promoting pulses. In spite of these efforts, it is observed that pulses are lagging behind cereals in terms of increase in area and productivity. This is mainly due to high yield variability in the production of legumes, and the preference of farmers for high-yielding cereal crops driven by skewed price support and cereal-centric policies ${ }^{3}$. It was pointed out that horizontal area expansion of $2.65 \mathrm{~m}$ ha in the Indo-Gangetic Plains (IGP) is possible by inclusion of legumes as sequential, mixed or inter-crops in different cropping systems ${ }^{4}$. However, the benefits of such arrangements need to be vigorously pursued with farmers and policymakers, who often ignore the long-term benefits and focus instead on short-term returns. This leads to an underestimation and thus under-valuation of ecosystem services provided by legumes. With the prevailing

*For correspondence. (e-mail: girish.stat@gmail.com) 